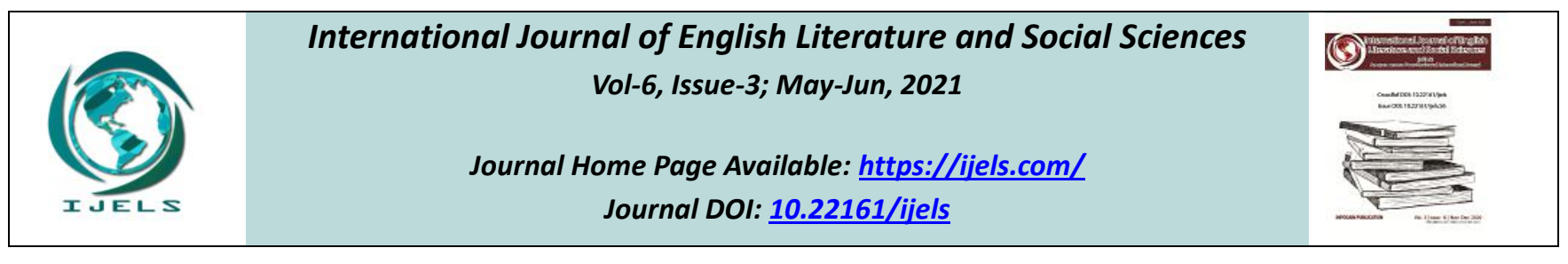

Peer-Reviewed Journal

\title{
Study of Ma Jianzhong's Patronal Activities of Translation
}

\author{
Tian Xibo
}

Dongfang College of Zhejiang University of Finance and Economics, China

Received: 12 May 2021; Received in revised form: 10 Jun 2021; Accepted: 20 Jun 2021; Available online: 29 Jun 2021

(C2021 The Author(s). Published by Infogain Publication. This is an open access article under the CC BY license

(https://creativecommons.org/licenses/by/4.0/).

\begin{abstract}
As a translator of the influential politicians and diplomats such as Li Hongzhang, Guo Songtao and Zeng Jize, Ma Jianzhong once assumed the task of translation of credentials by Patrice de MacMahon, diplomatic treaties and documents between Korea and the Qing Dynasty. Besides, he was once a teacher of Liang Qichao in studying Latin, persuaded Gu Hongming to come back to China to serve the country and compiled a book about navy construction.By analyzing Ma Jianzhong's patronal activities in translation theory, practice and to the two influential translators, as well as establishing translation academies, the readers can have a better understanding of the translation contribution of Ma Jianzhong.
\end{abstract}

Keywords-Ma Jianzhong, patronal activities, translation.

\section{INTRODUCTION}

In his Translation, Rewriting and the Manipulation of Literary Fame, Lefevere, a representative of the cultural school of Translation Studies, attributed the main factors affecting translation to poetics, ideology and patronage, among which "sponsor"is an important factor. Lefevere points out that patrons are here are ...the powers (persons, institutions) that can further or hinder the reading, writing, and rewriting of literature. Lefevere identifies three elements to this patronage: the ideological component; the economic component; the status component. Lefevere holds that the most vital consideration is the ideological one, which refers to the translator's ideology, or the ideology imposed upon the translator by patronage. (Lefevere,2004 )Translation sponsors cover a wide range, either as direct sponsors and sources of funding, or as organizers of translators, who will have a direct impact on translation activities in terms of translation choice, translation content, translation methods and strategies. Unfortunately at present, there are few achievements in the field of translation Studies on the translation activities in the late Qing Dynasty from the perspective of translation sponsors. Therefore, this paper explores Ma Jianzhong's translation activities from the perspective of translation sponsors and aims to give some hints to researchers.

Ma Jianzhong (1845-1900), also called Ma Meishu, was born in Dantu, Jiangsu Province. He was born in a family of Catholicist and finished his education at Xuhui Public School in Shanghai. He was as famous as and his brother Ma Xiangbo. (Zhang Ruogu, 1939) He was a prominent Chinese diplomat, thinker, grammarian as well as a translator. As is said inThe Draft of the History of the Qing Dynasty, Ma Jianzhong is fond of learning from the childhood, he masters classics and history, and is good at ancient prose, European languages such as English, French, Greece and Latin.( Zhao Erqi, 1981)

Ma Jianzhong was once the translator of $\mathrm{Li}$ Hongzhang, one of the leaders of the Westernization group, and Guo Songtao and Zeng Jize, the ambassadors of the Qing dynasty. He participated in many important 
diplomatic activities, and served translator and interpreter in a lot of oral and written translation work; Ma Jianzhong also compiled Essentials of the France Navy, and served as a Latin teacher for Liang Qichao, a reformer of the reformists. He also successfully persuaded Gu Hongming, who had worked in the colonial government of the Singapore Strait to return to work for China. Ma Jianzhong's translation patronal activities can be described as multi-faceted and multi-angle.

\section{MA JIANZHONG'S PATRONAL ACTIVITIES IN HIS TRANSLATION PRACTICE}

In 1876, Ma Jianzhong went abroad as an entourage to study at the Paris Political Institute in France. At the same time, he also served as an interpreter for Guo Songtao who is ambassador of the Qing dynasty to Britain and Zeng Jize who is ambassador of the Qing dynasty to Britain, Russia and France. During this period, Ma Jianzhong provided many important translation for the two ambassadors in both oral and written translation. Ma Jianzhong has also been appointed to represent or accompany Guo Songtao to attend some important meetings on many occasions, and also acts as an interpreter and translator.

In 1880, Ma Jianzhong returned home and soon became Li Hongzhang's Deputy Director, assisting Li Hongzhang in many important diplomatic and translation work. In March 1880, the Qing government abolished the "Treaty of Rivakia" signed by Chonghou, Ma Jianzhong was assigned to meet ambassador of the United Kingdom and the France ambassador to win the support of a third country. Ma Jianzhong's early diplomatic and translation work paved the way for Zeng Jize's successful revision of the Treaty with Russia and decreased part of the losses brought to China by the Treaty.

On March 20th,1881, Ma Jianzhong and Zheng Zaoru drafted the Treaty of Commerce between North Korea and other countries. The text of the Treaty was written in both Chinese and Korean, with the Chinese text as the original and the Korean text as the copy, which reflected $\mathrm{Ma}$ Jianzhong's understanding of the relationship between the source text and the target text in the process of translation, and he was praised by Li Hongzhang for this action.
On June 23, 1882, Ma Jianzhong and Ding Ruchang arrived in Incheon, North Korea, and they met Zhao Ningxia and JinHongji, the chief and Deputy envoys of the North Korean government, and Brandt, the German public envoy to China. The signing of the treaty took the previous British and American treaties as a precedent. Because few people knew German, they used a French volume for proofreading. Similar to the previous time, Ma Jianzhong collated and translated documents for the negotiation, providing oral and written translation.

In addition, Ma Jianzhong also assisted in the revision of TheKorean-British Trade Treaty andThe Korean-French Trade Treaty on April 21,1882. He also collated and translated relevant documents, and provided translation patronage for the revision process.

In 1893, Ma Jianzhong left Li Hongzhang's shogunate and transferred to live in Shanghai, translatingsome books, occasionally doing some translation work for Li Hongzhang such as the translation of The Treaty of Shimonoseki. Until the middle of August of 1900, he was assigned to translate Russian messages and died of fatigue.

\section{MA JIANZHONG'S VIEW OF “GOOD TRANSLATION"}

In 1893, Ma Jianzhong left Li Hongzhang's shoguns and returned to Shanghai to "re-managed his old career" and specialized in translating. In his famous book $O n$ the Establishment Translation Academies which was completed in 1894 , he put forward his translation idea, since it's difficult to translate and what shoulda translator do? In his daily study, a translator should first compare the similarities and differences of the source text and the target text, and to examine and analyze the complexity and simplicity of the words, and do his best to reproduce the style of the source text. If you are to translate a book, you should try to imitate the style and tone of the source text.Only when there is little differences between them, it is called a "good translation".(Ma Jianzhong, 1894)

At the beginning of this passage, Ma Jianzhong pointed out the importance of translation for strengthening country. Ma Jianzhong believed that only by translating books can we know ourselves and our enemies and win forever. Therefore, it is an urgent task to put the translation 
of books to an urgent place. And then he emphasized that Western countries do not hesitate to hire translators, set up translation libraries, and specialized in translating the original articles of government decrees and education, rather than just for the purpose of practice use. In this way, can they provide reference for the ruling scholars.

In this passage, Ma Jianzhong puts forward specific measures to deal with "the translation of books cannot be delayed" and "the translation of books has to be done in time," and puts forward the highest standards and goals for translators." Only in this way, can the reader benefit from the translation as it is almost the same as reading the original text." The theory of "good translation" is a guiding principle for training qualified translators, changing the condition of poor translation quality.

\section{PATRONAGE FOR TWO TRANSLATORS}

In 1881, Ma Jianzhong was assigned to go to Southeast Asia to visit Saigon, Singapore, Calcutta and other places to investigate the import of opium, and negotiated with the British and Indian authorities on the issue of opium monopoly. In Singapore, Ma Jianzhong happened to meet $\mathrm{Gu}$ Hongming, a "master of Chinese and Western Studies" who was proficient in nine languages and received thirteen doctoral degrees. After three days of meeting with $\mathrm{Gu}$ Hongming, Gu's thoughts changed dramatically. He immediately submitted his resignation to the colonial authorities. Before waiting for a reply, he returned home on the first steamboat. In 1885, Gu Hongming became Zhang Zhidong's Deputy Governor of Guangdong. After specializing in Sinology in Hong Kong for several years, $\mathrm{Gu}$ Hongming spared no efforts to publicize Chinese culture and creatively translated three books of The Four books to the West, namely The Doctrine of the Mean, The Great Learning and the Analects of Confucius, which played an important role in the process of the spread of Eastern learning to the West.

In the autumn of 1896, Liang Qichao went to Shanghai to set up Current Affairs Newspaper and he lived next to Ma Jianzhong. Liang Qichao learned Latin from Ma Jianzhong and discussed other learnings together.(Jiang Wenye, 1988 ) According to Liang Qichao's Chronicle, I have been studying Latin for more than 10 days, Mr. Ma volunteered to teach me, each day I studied for two hours, so there is no obstacles and I can read all the books within a year. Ma Jianzhong's patronageto Liang Qichao indirectly provided translation patronage for Liang Qichao's translation careers in the future.(Ding Wenjiang, 1983)

\section{CONCLUSION}

By analyzing Ma Jianzhong's patronal activities in translation theory, practice and to the two influential translators, as well as establishing translation academies, the readers can have a better understanding of the translation contribution of Ma Jianzhong.At the same time, Ma Jianzhong's translation practice was based on his political and diplomatic activities. As Li Hongzhang's assistant, Ma Jianzhong's translation practice was subject to Li Hongzhang and the Qing government at that time, and his translation practice is restricted by the guiding ideology of his political group.

\section{REFERENCES}

[1] Bassnett, Susan and Andre Lefevere, ed. Translation, History and Culture[M].London:Cassell, 1990.

[2] Ding Wenjiang, Edited by Zhao Fengtian. Liang Qichao's Chronicle. Shanghai: Shanghai People's Publishing House. 1983.

[3] Harish Trivedi, ed. Post-colonial Translation: Theory and Practice[M]. London and NewYork: Routledge,1996.

[4] Lefevere, Andre. Translation, Rewriting and the Manipulation of Literary Fame[M]. Shanghai: Shanghai Foreign Language Education Press, 2004.

[5] Jiang Wenye. Ma Jianzhong Chronicle[M]. Shijiazhuang: Hebei Education Press. 1988.

[6] Ma Jianzhong. On the Establishment Translation Academies.Notes on Shikezhai [M]. Beijing: Zhonghua Publishing House. 1894.

[7] Zhang Ruogu. Chronicle of Ma Xiangbo[M]. Beijing : Commercial Press, 1939.

[8] Zhao Erqi, keYingqi, et al..Draft of the Qing History[M], Volume 446. Taiwan: Hong Publishing house. 1981.

This article is part of the research results of "On Ma Jianzhong's translation activities" (2020dfy004) 